\title{
Managing Talent; Twenty Commandments about Talent Management
}

\author{
Syed Shabib-Ul-Hasan \\ (Department of Public Administration University of Karachi, Pakistan)
}

\begin{abstract}
Today's highly competitive world, with its assistant paradigms, has altered the way human productivity is evaluated. Human capital has now usually been appraised in terms of its attainment, achievement, accomplishment, consumption, growth and retention. However, this has put a strict stipulation on modern-day HR professionals. These days HR professionals are predicted to attract suitable individuals, select the most remarkable among them, and then train them in order to polish their skills according to the job requirements. The job of the HR professionals does not stop here; it is also required that these individuals are retained by organization in pursuance of organizational goals and objectives. Consequently, a serious issue for every HR manager in order to endure this 'War for Talent' is to struggle against an inadequate pool of eligible available candidates while it tries to fill the job void as experienced employees leave the organization. The aim of this paper is to elaborate the importance of identifying, nurturing and holding the best talent. Furthermore, it also emphasize the complexity in attracting, encouraging and holding the best employees in an organization, which has made the understanding of the meaning of Talent Management more decisive for managers.
\end{abstract}

Key words: Employee, Human Resource, Organization Development, Performance, Talent Management

\section{Introduction:}

The complexity and diversity of the issues surrounding Talent Management in an organizational setup can be appreciated by the fact that it has been variously defined and explained by assorted HR professionals. "Talent management is the incorporated process of ensuring that an organization has a never ending supply of highly productive and dynamic persons in the correct job, at the correct time". James M. Hunt declares that "encouraging talent is one of the most significant parts of managing talent at workplace". Usually managers do not motivate their employees on the pretext that employees are aptly compensated financially-hence, there is no need of motivating them. On the other hand, managers motivate and encourage their children at home when they do something good. Therefore, managers must encourage employees working under his supervision in order to enhance their productivity at workplace. In his The Talent Management Handbook, Berger notes that "the character issue can be recognized during the hiring process of the employees". Managers have usually been considered as those individuals that can bring about significant improvement in their subordinates' work efficiency provided that they want their workers to rise to heights of success. It is also believed that managers help their subordinates to construct relationships at workplace. Marshall Goldsmith declared that "telling the truth about the talents is very essential for managing the talent at workplace". It is also claimed that the responsibility to identify specific talents generally devolves on a concerned individual himself, and it is he who has to ensure that the "right people" appreciate them. Everyone at the workplace has the inspiration to be like one's role model, but the bottom line is that one has to have one's own codes defining the way forward. It can usually be observed that professionals in their later ages of life seem to be more satisfied and contended with their personal and professional lives as compared to professionals in earlier phases. Young professionals generally have misapprehensions regarding continuous career progression, considering that what they have gone through was worse - that, in fact might not be in case. Similarly, these young professionals garner overblown expectations concerning future. Nevertheless, this perception is completely in line with the motivational course en route for continual development and gains. According to Robert Frank, albeit future is for the young, but the nonexistence of experience professionals could marshal impractical decision-making and hindrance for achieving success because they are the people with more experience, knowledge and perhaps wisdom. Jamie Notter, however, believes that the quicker the people can initiate to communicate to others, the greater the possibility that they can form workplace relationships that count.

The above discussion has very clearly accentuated the fact that the resolution is not just about discovering the correct retention mechanisms, but it starts from the very beginning by planning ways to attain the correct people for the correct jobs. Talent management is the incorporated process of ensuring that an organization has persistent supply of highly productive and dynamic persons in the correct job at the correct time. Rather than a one-time event, talent management is a nonstop process that plans talent needs, fabricates an image to magnetize the very finest, and guarantees that new hires are directly productive. Moreover, it helps to 
retain the most excellent, and assists the continuous movement of talent to where it can have the most impact in the organization.

Managers can talk about talent management until they are blue in the face, but very few would be having any idea of how it could be done in an organization. It is therefore imperative to brood over the basics of talent management process and to apply it for the mutual benefit of organization and employee.

\section{Twenty Commandments about Talent Management}

\subsection{Have Coherent Focus}

In order to apply a comprehensive and concrete talent management process, one must first pose the question "Why?" This must be followed by a calculated approach with rational and relevant answers. It may initially cause certain problems in recruiting, providing orientation, or portraying a right image. If the question has all of these dimensions then probably it would be very difficult to resolve the issue, and might be considered as economically insolvent. However, if different dimensions could be addressed specially, one may identify those regions that will provide the genuine payoff.

It is therefore very important that the manager should know how to spot the right talent. Managers should have the necessary acumen to interview, hire, manage performance, and grow people. If they don't possess these skills naturally, then the organization must ensure that they are equipped with requisite skills, since programs don't manage talent but people do.

\subsection{Managing Talent is actually about Management}

Human Resources have an important support role to play provided that HR section is necessarily equipped in the tasks of organizational development. Therefore, one must not await initiatives from the HR department. Since it is the task of the managers to have an expertise to lead initiatives, managers must themselves have the acumen as what necessary steps have to take. However, if the HRD is strong in organizational development, it can be of great assistance in supporting the efforts and being intimately involved in planning, and explaining what is happening and why, and the necessary follow-through. Initiative and ideas may range from recognizing the character at the time of acquiring talent to making effort in developing a work model based on good quality relationships at workplace. Besides that, it is the mentor's responsibility to observe all relevant issues and assist them in mastering the finer points.

\subsection{Encourage Talent}

Encouraging talent is one of the most significant parts of managing talent at workplace. It is noticed that individuals at job are profoundly interested in expressing their own strong points. Instead of leaving it to become a form of self-applause, the management must identify and encourage the intrinsic aptitude in employees, since this would lead to a higher motivation in them to contribute to their full potentials. Moreover, it appears that people are already involved and dedicated over a longer time horizon provided their energy, dynamism and flairs are considered of being worth. It must be clear to the managers like the back of their hand that a good leader is one who can motivate his team members' efforts. If he fails to do this, then this entails that he is not extracting the true potentials out of his employees. Sometimes the manager may think that since the employees are getting salary from the organization they should not be told what to do or how well they have done.

\subsection{Your Commitment Matters}

It seems very incongruous that why sometimes employee, including executives, store their CVs and look for other opportunities, while saying yet that they are satisfied with their current job. In actual, it is similar to a situation where you orally promote growth but your actions do contrarily. Performance enhancement of employee requires showing and executing complete devotion and sincerity towards whatever you are doing. It is critical of talent management to show such a level of dedication that subordinate consider you as a symbol of loyalty and draw motivation from it for their part of work. Management has to design ways and system where the employee can be contributing with the same zeal and commitment which the work demands from its employees. Simple idea of appreciating the employees' minute accomplishments can do wonders in drawing out best from the subordinates. If, on the contrary, manager believes it as a problem and is reluctant to do such an exercise, he would find it difficult to build a strong and hardworking team.

\subsection{Good Grief}

Each day, we all try to discover new things or find a bit new. It is true that a portion of our day is used up being a child once more, at the same time as it gets nearer to struggling with a latest difficulty that requires a resolution. It is possibly for everyone that they might need a small number of cheering and inspiring words of recognition when exhibiting a talent that facilitates the organization. It is known by everyone that an individual's mind abhors emptiness. It has also been observed that in the dearth of precise information, people 
will generate their own narratives to fill the space. Unluckily, we humans frequently make an additional negative reality apart from the reality that exists. Therefore, the lack of recognition and support can very simply twist into the sensitivity of a "critique". Such as, if my boss is not letting me know that I am doing sound, then I must be doing poorly.

\subsection{Build Your People}

One of the most imperative activities in any organization is to understand employees for who they are, apprehending what they can be, and helping to take them reach there. It is important to note that every organization hires the most suitable people they can discover. However, it must not be ignored that on grounds of dissatisfaction, retention of employees at times becomes a serious concern and necessitates another hunt for talent. Employees with a high morale obtain performance appraisals that strengthen their standings in the organization. Employees, at every level, know about deficiencies they have and factors that obstruct them in pursuance of their objectives. Management must make serious attempt to locate ways to bridge the gaps by enhancing their skills personally and professionally. Out of various reasons, most of the times people are fired out of the organization because of matters related to their personalities, their incapability in understanding the relationships in the organization both with people or system, and also due to their failure in plucking such deficiencies. "

\subsection{Manage as Trainer}

Managers can train their subordinates if they want to see them growing and reaching the heights of success, because it helps employees to construct relationships at workplace and lets the managers know about their employees. Managers should provide due assistance to their employees to build their talent which may at time may not be obvious. Contrarily, if the manager is not interested in unearthing the talent due to any excuse whatsoever, it reflects that he does not have the time or fondness to train his employees. It is important to highlight the fact that if the managers want their endowment to be given in accordance with what they deserve, they should help people around them to explore precisely their true potentials by giving them the confidence to express their true colors. Being a manager, initiate thinking process, observe and collect evidence and look for required assistance, if things seem to be going out of control. In addition to it, share your opinions on accuracy, aptitude, and build people by seeing them clearly.

\subsection{Express Equitable Ethics}

In order to be regarded as an individual who recommends genuine value in a talent management discussion, one ought to be a person who genuinely appreciates his employees if they perform well. Recognition of a true talent requires a clear heart reflecting the true and unbiased reflection of the talent. Besides that, it is a duty of the manager to let the employees know if their performance fails to meet the organizational standards, and to facilitate them to meet the expectations of the organization. Manager at the place of work may engage the employee in group activities to make employee understand their unexplored talent and use it in the mutual interest of both the employee and the organization. Apart from the above, the managers can also assist the workforce through workshops and seminars to refresh their minds and gain knowledge. It helps to learn from a different perspective and guides them to open up their mind and learn explicitly about talent they possess.

\subsection{Nurturing Talent}

Individuals always look for opportunities where they could be hired in an organization where their talent could be recognized and harnessed, thereby making him grow along with the organization instead of living in a working world of changes. With the business environment changing so quickly that it has become imperative for the management to facilitate the organization and the employees both with the opportunities to grow and explore their potentials. Managers must be smart enough to find compatibility between the organization, talent and the external/ internal changes on a continual basis. Nobody can abruptly go unintelligent and dull; this only entails that something else now needs to be changed. There are several numbers of concerns where the organizations and human resources lock their horns in a talent divergence in view of the changes. It is the responsibilities of the manager to tap ways to transform such divergences into something mutual beneficial.

\subsection{Coaching the Leadership}

Leadership coaching plays a significant part in the talent management process at workplace. Since leadership coaching and leadership development emit a serious amount of vagueness in the air, the resultant coaching job becomes indistinctive. It is important to know at this juncture that the triumph or collapse of the coaching or consulting activity lies majorly in how the contracting phase has gone through. Furthermore, the manager needs to be comprehensible and logical about the initiation of training application and that the understanding of the reason and focus of the training has to be clearly understood by everyone involved. Although Leadership is an eye-catching phrase, perhaps the genuine issue would generally be organizing team 
performance, operating healthier congregations, or initiating conversations with colleagues in other corporate locations. It must not be forgotten that some of the skills are inherently there and cannot be inculcated through learning other ways. If one is asked about how to learn leadership the best, the most thoughtful answer would be through leading. Therefore, be prepared to suggest expanded responsibility, and help in making people grow by lifting them up.

\subsection{Make Talent Visible}

Everyone wants their talents to be noticed at workplace; therefore the manager must make arrangement about letting employee exhibit their talent to the right people for receiving appreciation. Three things may be done by the management to let individual be able to manage it.

2.11.1 Personality Review: Evaluation of one's own personality is the key to success in an organization. It is important to let individual know about their strong areas themselves in order to be most effective.

2.11.2 Prohibition: It is also important for managers to make sure that individual pay due consideration to all his weaknesses. It helps to overcome the limitations and makes one successful, as an employee.

2.11.3 Pomp n Show: In order to portray the true potential, the employee should be allowed to share the ideas to display their talents. They should be given chance to lead the project, committee, or organizing event so that their potentials be noticed and accepted.

\subsection{Positive Expectations}

Most of the time we lead life based on what we perceive and expect. Workplaces are all about attitudes and perceptions, and in the presence of positive atmosphere, employees would make most of the time available. Individual expecting to be thriving have more chances of achieving it, whereas one expecting to fail has more chances to fail - this being a mind game. A manager's belief about his subordinates' performance will affect their feat. Most of the time performance appraisal and feedback get manipulated due to the implicit and explicit perceptions that the manager holds and convey. Furthermore, it gets transmitted to the employees and shapes their future performance, thereby affecting the manager's performance as well. It is therefore important to have a management that works for developing positive environment to guide the talent in the right direction. Manager transmitting positivity and self-fulfilling foresights would find it easier to enhance the positive performance out of his employee simply based on the notion that very often 'one get what he expect'.

\subsection{Understanding Succession Planning}

Harnessing the talent to achieve the true potential requires spending some time administrating, having succession planning, or going through a performance assessment. By having this exercise, one can know that total talent conversations can morph into a partiality founded single understanding. Succession planning and understanding play a chief role in managing the talent at workplace. The idea is to abridge the talent management, acknowledging its soundness and peculiarity, and that succession planning is to be the component that ensures the overall smoothness. In addition to it, simplicity is also required to enforce discussion on the fundamentals to reach at a common understanding. However in process of succession development plans, managers have to make it clear that they are not promises, as very often they are communicated like this which adds to the frustration and makes it difficult to achieve continous high performance. In order ot have smooth harnessing of talent, promise of succcession could only be made if it carries more chances of turning into reality.

\subsection{Adapt the Organizational Culture}

The concept of traditional career seems to have faded away in modern times with so much job switching and career shifts happening around. It is believed that in order to pursue a genuine career one must rather look at work life as a series of projects. If it happens so, there is a subsequent need to develop managers whose dynamism encompasses the capability to progress and build new relationships and situations. However in the process of transformation, managers needed to be inculcated about the difference between facsimileing successful systems and trying to unconsciously copy the actions of management techniques that have worked before. It is good to take inspiration, but always try to have a sound comprehension of the situation to be able to take the right course of action. There is no harm in finding or comprehending the situation and the context in which some technique had worked in the past. Such an approach will help in building a set of ideologies and philosophies to rely in leading organizational life.

\subsection{Demographic Features and Perception}

Perceptions about life satisfaction and life expectation have relationship to age as older people have more things to talk about life satisfaction compared to younger ones who have more to say about life expectations. Managers have to make sure that the employee could be able to regulate emotionally to whatever life throws their way. Most people's life satisfaction actually changes very minutely through the years. The younger ones have a misapprehension of continual improvement, seeing the past as worse than it actually was 
and the future as enhanced than it turns out to be. This illusion is steady with their motivational direction toward nonstop growth and gains. Despite the future belongs to the young, it could be argued that the absence of older workers may lead to impractical decision-making subject to over emphasis on abilities. Adding realism, knowledge, practice to optimism and energy can work for channeling the talent through the reins of experience to get most out of the talent available. It adds another dimension to decisions and implementation that possibly will provide a real pathway to move ideas and inspirations forward.

\subsection{Order Your Space}

Managers have to accept the responsibility to tame the talent towards the ultimate priorities of both employee and the organization. Although this is an instinctive propensity for organizing and arranging one's own agenda, managers should convince that the employee draws sufficient satisfaction to keep his association with the organization as the top priority. However it does not routinely take account of the aptitudes, capabilities, and capacities of the employee only, but the time and priorities of the organization as well. Managers should also be required to help individuals identifying their space and holding it for mutual benefit. It is also important to communicate very clearly to them as what they need to be doing and the extent of effort required of them to manage their space individually not only in the organization but also in life. If one has the clarity about it, then one is most likely to uphold things in their appropriate place.

\subsection{Humane}

Communication with people is decisive since it provides a better chance of initiating a long lasting relationship, which also counts in bringing out best out of people. It actually means that when discussing about the organization, it is always important to speak about the people with their names or to refer to them with appealing attributes about them that you value. While pointing out the title and role, it is equally important to narrate about their responsibilities towards accomplishments of the developmental objectives. Moreover, in doing so, mentioning their distinctiveness and skill-set actually humanizes their roles that need to be filled with. Needless to say that in the absence of the humanistic touch in the communication it is hard to get best out of people. Talent is about human so it has to be discussed, acknowledged and communicated for people to work with each other or assist each other which is very difficult to have if people do not actually know each other!

\subsection{Coating of Talent}

Talent requires harnessing and guidance to extract mutual benefit for employee and organization both. Wisdom, discernment and integrity play a major role in making the talent grow stronger with the business. Wisdom is a capability to recognize inner qualities and relationships. Good judgment comes under wisdom and it is really required in an effective professional. Furthermore, discernment is the power to make a distinction and decide on what is factual or suitable or admirable. It is the feature of being able to grasp and understand what is vague. Moreover, integrity is a firm devotion to a set of laws of especially moral or artistic values, and also the class or state of being complete or exclusive. These characteristics should be treated as the guiding characteristics of the actual talent posses by the employee. It is the responsibility of the manger to make individual understand the true meanings of these characteristics under all situations. Employee must be groomed to make a good name rather than looking sycophancy acknowledgement or financial rewards.

\subsection{Creative Talents}

Creative talents are not a standardized and uniform chunk of material but it must have something to do with individual's own unseen, inventive essence. Such individuals keep themselves engaged in experimenting with new ideas, thoughts and inspirations. The unique trait about these creative talents is that they visualize very differently and truthfully within their imaginative globe. This new breed of talent may form a new association as a result of conjecturing, philosophizing, daydreaming, and hypothesizing. Managers must be able to make a distinction between those that tend to focus on physical creativity and those that live in the world of ideas and concepts. Furthermore, another way to identify this type of creative talent is to observe those people who act out their ideas in expressive ways. For successful talent management such individuals needed to be identified, hired, trained and retained in the organization because these are the people who can reenergize the remaining staff of the organization with their ingenuity and inspirational works.

\subsection{YOU}

Over the course of a lifetime, what one brings to one's own life and work is dynamism and vitality. Talents and interests modify and develop; one may turn out to be more closely aligned with principles, beliefs, ideologies, and prioritize the unique transformation as a result. The dynamism is the core factor that propels the persistent response, and makes the developmental discussions more critical and important. In addition, people attain the level of grip over their skills and talent only by way of pursuing, practicing and perfecting it with in their routine life. It could be argued as the better way to show how one can direct and guide routine activities into being 
intensified and achieve bigger tasks for the company and individual both. It is important for the manager to let individual to understand the depth of the talent he posses to be able to get efficient results. In a way manager should be providing purposeful career counseling in helping employee could paint his career with the genuine colors and do justice with the talent he possesses.

\section{Conclusion}

There is no denial from the fact that organizations are reaping rewards of efficient talent management practices, therefore they are taking it seriously. Such organizations require their managers to be taking a broader view to talent management from attracting the candidates and picking the excellent ones, to preserving and growing leaders, and placing employees at the core. In order to flourish and prosper in today's rapidly altering and highly competitive marketplace, a deep focus must be applied in order to line up human capital with business plans, policies, strategies and objectives. Furthermore, with fast varying skill sets and job requirements, managing talents becomes an increasingly complicated challenge. To accomplish such a challenging task managers must be trained and furnished with precise talent evaluation methods. As a result of executing an effectual and efficient talent management strategy, as well as incorporated data, methods, practices and reasoning, organizations can definitely ensure that there are right people for the right job in order to enhance the organizational promptness for the future.

\section{References}

[1] R.F. Silzer, R. Silzer, B. E. Dowell, Strategy-Driven Talent Management: A Leadership Imperative (Hoboken, NJ: John Willey \& Sons, 2009).

[2] James M. Hunt, Joseph R. Weintraub, The Coaching Manager: Developing Top Talent in Business (California: SAGE Publications, 2010)

[3] Lance Berger, L. Dorothy Berger, D. The Talent Management Handbook: Creating a Sustainable Competitive Advantage by Selecting, Developing, and Promoting the Best People (New York: McGraw-Hill Prof Med/Tech, 2010)

[4] Goldsmith, M. Carter, L., Best Practices in Talent Management: How the World's Leading Corporations Manage, Develop, and Retain Top Talent (Hoboken, NJ: John Willey \& Sons, 2010)

[5] Shukla, R., Talent Management: Process of Developing and Integrating Skilled Workers (Global. India Publications,2009)

[6] Frank, R. Silzer, R., Dowell, B. (2009) Op. Cit.

[7] Jamie Notter, J., Grant, M., Humanize: How People-Centric Organizations Succeed in a Social World (Indiana : Que publishing, 2011)

[8] R.F. Silzer, R. Silzer, B. E. Dowell, (2009) Op. Cit.

[9] Kevin Oakes, Galagan, P. The Executive Guide to Integrated Talent Management (Danvers MA: American Society for Training and Development 2011)

[10] Schiemann, A.W. Reinventing Talent Management: How to Maximize Performance in the New Marketplace (Hoboken, NJ: John Willey \& Sons, 2009).

[11] Goldsmith, M. Carter, L. (2010), Op. Cit.

[12] James M. Hunt, Joseph R. Weintraub (2010) Op. Cit.

[13] Galagan, P. (2011), Op. Cit.

[14] Thorne, K. Pellent, A. The Essential Guide to Managing Talent (London: Kogan Page Publishers, 2007).

[15] Berger, L. A. Four Steps to Creating a Talent Management System. In D. R. Berger \& L.A. Berger (Eds.), The Talent Management Handbook: 2. (New Delhi: McGraw-Hill Publishing, 2004c)

[16] James M. Hunt, Joseph R. Weintraub (2010) Op. Cit.

[17] Goldsmith, M. Carter, L. (2010), Op. Cit.

[18] Cross, A., Talent Management Pocketbook (Alresford, UK: Management Pocketbooks Ltd, 2007).

[19] Hay Group, Talent Management - What the Best Organizations Actually Do, London: Hay Group, 2005).

[20] Brent Davies, Barbara J. Davies, Talent Management in Academies, International Journal of Educational Management, Vol. 24 Iss: $52010418-426$

[21] http://www.allthingsworkplace.com/managing_your_companys_talent/

[22] Peters, T., Talent: Develop it, Sell it, Be it (Noida, India: Dorling Kindersley, 2005)

[23] Conger, J. A. \& Fulmer, R. M. Developing your Leadership Pipeline, Harvard Business Review, Dec. 01,2003

[24] Scullion, H., Collings, D.G. , and Caligiuri, P Global Talent Management, Journal of World Business, 45 (2) $2010105-108$.

[25] Gandossy, R. and Kao, T. Talent Wars: Out of Mind, Out of Practice, Human Resource Planning, 27 (4) 2004 15-19

[26] Michaels, E., Handfield-Jones, H., \& Axelrod, B. The War for Talent (Massachusetts: Harvard Business School Press, 2001)

[27] Gratton, L. \& Ghoshal, S. Managing Personal Human Capital: New Ethos for the 'Volunteer' Employee. European Management Journal, 21(1) 2003 1-10.

[28] Lévesque, L. Breakthrough Creativity: Achieving Top Performance Using the Eight Creative Talents (California: Davis-Black Publishing, 2001)

[29] Vaiman, V., Smart Talent Management: Building Knowledge Assets for Competitive Advantage (Cheltenham UK: Edward Elgar Publishing,2008) 